University of Nebraska - Lincoln

DigitalCommons@University of Nebraska - Lincoln

2012

Ceramic thin film thermocouples for SiC-based ceramic matrix composites

John D. Wrbanek

NASA Glenn Research Center, John.D.Wrbanek@nasa.gov

Gustave C. Fralick

NASA Glenn Research Center

Dongming Zhu

NASA Glenn Research Center

Follow this and additional works at: https://digitalcommons.unl.edu/nasapub

Part of the Physical Sciences and Mathematics Commons

Wrbanek, John D.; Fralick, Gustave C.; and Zhu, Dongming, "Ceramic thin film thermocouples for SiCbased ceramic matrix composites" (2012). NASA Publications. 97.

https://digitalcommons.unl.edu/nasapub/97

This Article is brought to you for free and open access by the National Aeronautics and Space Administration at DigitalCommons@University of Nebraska - Lincoln. It has been accepted for inclusion in NASA Publications by an authorized administrator of DigitalCommons@University of Nebraska - Lincoln. 


\title{
Ceramic thin film thermocouples for SiC-based ceramic matrix composites
}

\author{
John D. Wrbanek* , Gustave C. Fralick, Dongming Zhu
}

NASA Glenn Research Center, 21000 Brookpark Rd, Cleveland, Ohio 44135 USA

\section{A R T I C L E I N F O}

\section{Article history:}

Received 4 January 2012

Received in revised form 10 April 2012

Accepted 12 April 2012

Available online $\mathrm{xxxx}$

\section{Keywords:}

Thermocouples

Thin films

Indium oxides

Zinc oxides

Ceramic matrix composites

High temperature environments

\begin{abstract}
A B S T R A C T
Conductive ceramic thin film thermocouples were investigated for application to silicon carbide fiber reinforced silicon carbide ceramic matrix composite ( $\mathrm{SiC} / \mathrm{SiC} \mathrm{CMC}$ ) components. High temperature conductive oxides based on indium and zinc oxides were selected for testing to high temperatures in air. Sample oxide films were first sputtered-deposited on alumina substrates then on SiC/SiC CMC sample disks. Operational issues such as cold junction compensation to a $0{ }^{\circ} \mathrm{C}$ reference, resistivity and thermopower variations are discussed. Results show that zinc oxides have an extremely high resistance and thus increased complexity for use as a thermocouple, but thermocouples using indium oxides can achieve a strong, nearly linear response to high temperatures.
\end{abstract}

Published by Elsevier B.V.

\section{Introduction}

Silicon carbide fiber reinforced silicon carbide ceramic matrix composites ( $\mathrm{SiC} / \mathrm{SiC} \mathrm{CMCs}$ ) applied as components of airframe and propulsion systems are expected to allow higher temperature operation along with a significant weight reduction in systems [1]. Implementation of these ceramics requires innovative environmental barrier coatings (EBCs) currently under development for CMC systems [2]. Measurements of heat flux and thermal stress of the EBC on CMC systems are necessary to allow their full characterization and enable their production as propulsion system components. To that end, sensors to measure high temperature and strain are being advanced that will allow fabrication of more durable components through improved models of component characteristics.

Development of thin film sensors for surface measurement is an active area in propulsion system research that can meet these measurement needs. The sensors include those for strain, temperature, heat flux and surface flow that will enable critical vehicle health monitoring and characterization of components of future space and air vehicles [3], providing unique measurements for high temperature systems in a variety of environments.

The use of sensors made of thin films has several advantages over wire or foil sensors. Thin film sensors do not require special machining of the components on which they are mounted, and, with thicknesses less than $10 \mu \mathrm{m}$, they are considerably thinner than wire or foils. Thin film sensors thus disturb the operating environment much less than

\footnotetext{
* Corresponding author. Tel.: +1216 4332077.

E-mail address: John.D.Wrbanek@nasa.gov (J.D. Wrbanek).
}

wire or foil sensors, and have a minimal impact on the physical characteristics of the supporting components [4].

Currently, the EBC-CMC systems under development for application as high temperature turbine vanes and blades are for use up to $1700{ }^{\circ} \mathrm{C}$. Sensors fabricated as part of an EBC-CMC system to allow in situ measurements during tests are needed to better characterize these systems. The application of ceramic films as sensors is utilized to satisfy these measurement requirements.

The need to consider ceramic sensing elements is brought about by the temperature limits of metal thin film sensors in propulsion system applications. Longer-term stability of thin film sensors made of noble metals has been demonstrated at $1100{ }^{\circ} \mathrm{C}$ for $25 \mathrm{~h}$ [4]. The capability for thin film sensors to operate in $1500{ }^{\circ} \mathrm{C}$ component testing environments for $25 \mathrm{~h}$ or more is considered critical for ceramic turbine engine development $[5,6]$. For future space transportation vehicles, temperatures of propulsion system components over $1650^{\circ} \mathrm{C}$ are expected [7].

For the high temperature environments that the sensor films will experience on an EBC-CMC system, the materials that can be utilized as conductive sensors are limited. The potential for cracking and delaminating of the films needs to be taken into account in selecting appropriate materials as well as the stability of the films that affect its electrical characteristics in oxidizing environments and in embedded EBC systems.

Thermal expansion mismatch stresses under thermal cycling conditions are considered the primary cause of film delamination, a first order effect of mismatches between the two materials' Coefficient of Thermal Expansion (CTE) [8]. The intrinsic strength and adhesion of the films to the substrate through reaction and diffusion are also important in designing the sensor systems, and dominate for thicknesses nearing the films' lattice constants $[9,10]$. 
The initial sensor material selection is based on the CTEs of the EBC$\mathrm{CMC}$ system and the film to be used as a sensor. The particular EBC-CMC system being addressed in this effort is a silicon carbide (SiC) CMC material with an aluminosilicate-based EBC [11]. The thermal expansion of the CMC is between $4.4 \times 10^{-6} \mathrm{~K}^{-1}$ and $5.1 \times 10^{-6} \mathrm{~K}^{-1}$, and the thermal expansion of the natural aluminosilicate crystal composite mullite $\left(3 \cdot \mathrm{Al}_{2} \mathrm{O}_{3}+2 \cdot \mathrm{SiO}_{2}\right)$ is well-matched to be between $4.5 \times 10^{-6} \mathrm{~K}^{-1}$ and $5.4 \times 10^{-6} \mathrm{~K}^{-1}[12-14]$. Allowing a mismatch of less than $\pm 50 \%$ from these values, only materials with thermal expansions in the range of $2 \times 10^{-6} \mathrm{~K}^{-1}$ to $8 \times 10^{-6} \mathrm{~K}^{-1}$ would be practical.

The more complex the thin film, the least likely the bulk characteristics will be achieved after sputter deposition and maintained during high temperature use, particularly in oxidizing atmospheres. In a summary of active oxidation temperatures and oxide scale protection of bulk ceramics, Samsonov et al. [15] report carbides and nitrides are particularly susceptible to deep oxidation with the notable exceptions of silicon carbide and silicon nitride that form silica scales. The borides of zirconium and titanium are reported to form very stable protective oxide coatings.

Also reported by Samsonov et al. to be resistant to high temperature oxidation are silicides of vanadium, molybdenum, tungsten and rhenium due to protective silica scales that are formed. However, we have seen oxide scales greater than $1 \mu \mathrm{m}$ form in $1 \mathrm{~h}$ at $800{ }^{\circ} \mathrm{C}$ on sputtered thin film samples of chromium silicide and molybdenum silicide exposed to high temperatures in an air furnace. This insulating scale makes the films difficult to use as thin film sensors in high temperature oxidizing environments for more than an hour without significant drift in electrical characteristics.

High temperature conductive oxides based on indium, tin, and zinc oxides $\left(\mathrm{In}_{2} \mathrm{O}_{3}, \mathrm{SnO}_{2}\right.$, and $\left.\mathrm{ZnO}\right)$ meet our criterion and have the benefit of not requiring a passivating scale overcoat for use at high temperatures [16]. These can be mixed with each other (as in the case of indium tin oxide), doped with aluminum or enriched with nitrogen to force different electrical characteristics. Recently, indium tin oxide (ITO: $90 \% \mathrm{wt}$ $\mathrm{In}_{2} \mathrm{O}_{3}+10 \%$ wt $\mathrm{SnO}_{2}$ ) and aluminum zinc oxide (AlZnO: $98 \%$ wt $\mathrm{ZnO}+$ $2 \%$ wt $\mathrm{Al}_{2} \mathrm{O}_{3}$ ) were identified as being particularly stable as thermocouples when deposited by sputtering in nitrogen [17]. With CTEs between 7 and $8 \times 10^{-6} \mathrm{~K}^{-1}$, the conductive oxides of ITO, $\mathrm{In}_{2} \mathrm{O}_{3}, \mathrm{ZnO}$ and $\mathrm{AlZnO}$ were identified as having good potential as high temperature thin film sensors on EBC-CMC systems.

For the thin film sensors to be evaluated as applicable to characterizing EBC-CMC systems, the films need to be shown compatible with both the EBC and the SiC-CMC that are in parallel development. Thus the challenge in testing the thin film sensors was how to test the fabrication of thin film sensors on anticipated EBC and CMC surfaces as close to the anticipated conditions as possible.

Previously, we demonstrated that fine-lined thin film sensors can survive on relatively rough $\mathrm{SiC}$ similar to that found on SiC-CMC surfaces [18]. The current surface roughness of raw CMC material ( $\pm 100 \mu \mathrm{m}$ or greater) is still unsuitable for fine-line patterned sensors with features $100 \mu \mathrm{m}$ or less. Therefore, $\alpha$-SiC disks (25 mm in diameter and $3 \mathrm{~mm}$ thick) that are typically used to test for $\mathrm{SiC} / \mathrm{SiC} \mathrm{CMC}$ compatibility were polished to $\pm 10 \mu \mathrm{m}$ and used as substrates. A heat flux sensor was fabricated by sputter-depositing a fine-lined AlZnO-N:ITO thermopile with a partial overcoat of mullite on the disk samples, as shown in Fig. 1, to investigate compatibility at high temperatures in future EBC-CMC systems.

As part of our continuing research on ceramic thin film sensors, we report here on candidate conductive ceramic films examined for thermocouple use. As discussed above, these films were chosen for their compatibility with the CTE of EBC-CMC systems and oxidation resistance. Tests were conducted on $1 \mathrm{~mm}$ thick, 99.6\% pure alumina substrates, and then survivability on an actual EBC-CMC system was explored. One EBC-CMC system that is showing potential for large scale use consists of multiple layers of barium-strontium-aluminasilicate (BSAS) [19]. Two $25 \mathrm{~mm}$ dia. samples of the BSAS EBC-CMC polished to $\pm 10 \mu \mathrm{m}$ were used. Being a preliminary candidate system, the EBC coatings developed flaws in polishing, and thus the sensors were not fine-lined, but fabricated using shadow-masks for the investigation.

\section{Experimental details}

Following the fabrication of a fine-lined thin film ceramic sensor recently demonstrated on a $\alpha$-SiC test piece simulating SiC/SiC CMC compatibility [18], tests were conducted to optimize ceramic thermocouple materials to use in the high temperature environments on EBC-CMC systems. Sample films of $\operatorname{In}_{2} \mathrm{O}_{3}, \mathrm{ZnO}$ and AlZnO were fabricated and tested for thermoelectric performance against platinum in a tube furnace at the NASA Glenn Research Center.

The films were fabricated on two samples, both on alumina substrates. One of the samples for testing the films is shown in Fig. 2. Samples consisted of three film strips approximately $2.5 \mathrm{~mm}$ wide by $75 \mathrm{~mm}$ long, overlapping on one end, and on the other overlapping on individual platinum film contact pads. The contact pads were sputtered-deposited first using shadow masks for 3 by $10 \mathrm{~mm}^{2}$ patterns. For bonding the platinum to the oxide substrate, a $150 \AA$ adhesion layer of aluminum was followed immediately by $1 \mu \mathrm{m}$ of platinum in the vacuum sputtering system.

All films were sputtered using $7.62 \mathrm{~cm}$ diameter unbalanced magnetron sources powered at $100 \mathrm{~W}$ RF. On each sample, the center film was sputtered platinum and the other films sputtered oxides. The two other films sputtered on the first sample were $\operatorname{In}_{2} \mathrm{O}_{3}$ and $\mathrm{N}$ : $\operatorname{In}_{2} \mathrm{O}_{3}$ (nitrogenenriched indium oxide), and on the second sample $\mathrm{ZnO}$ and $\mathrm{AlZnO}$. The films in the first sample were sputtered in a vacuum deposition system with a substrate-to-target distance of $25 \mathrm{~cm}$ and the second in a system with a substrate-to-target distance of $15 \mathrm{~cm}$.

The $\mathrm{N}: \mathrm{In}_{2} \mathrm{O}_{3}, \mathrm{ZnO}$ and AlZnO films were sputtered in a $1.07 \mathrm{~Pa}$ argon atmosphere mixed with $0.27 \mathrm{~Pa}$ nitrogen; the platinum and the initial $\mathrm{In}_{2} \mathrm{O}_{3}$ film had only argon with no additional nitrogen. The $\operatorname{In}_{2} \mathrm{O}_{3}$ and $\mathrm{N}: \mathrm{In}_{2} \mathrm{O}_{3}$ films used a $\operatorname{In}_{2} \mathrm{O}_{3}$ sputter target of better than $99.9 \%$ purity. The $\mathrm{ZnO}$ and $\mathrm{AlZnO}$ films used $\mathrm{ZnO}$ and $\mathrm{AlZnO}$ (98\%wt $\mathrm{ZnO}+2 \% \mathrm{wt}$

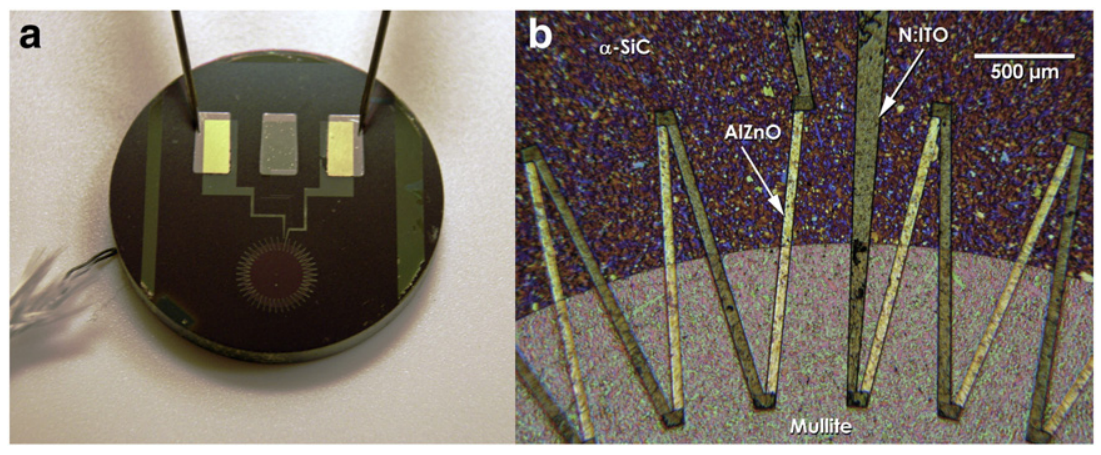

Fig. 1. Fine-lined AlZnO-N:ITO heat flux sensor on a $25 \mathrm{~mm}$ diameter $\alpha$-SiC disk: (a) during preliminary testing; and (b) a magnified view with films labeled. 


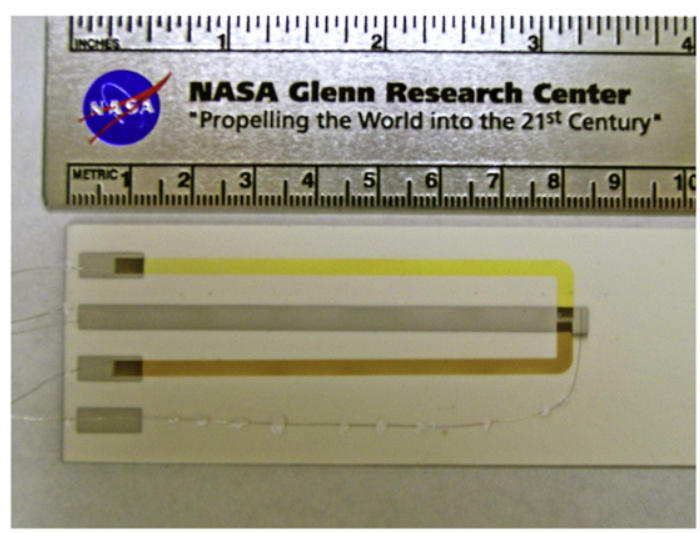

Fig. 2. Test sample composed of thin films of $\operatorname{In}_{2} \mathrm{O}_{3}$, Pt, $\mathrm{N}: \operatorname{In}_{2} \mathrm{O}_{3}$, and a PtRh alloy wire on an alumina substrate.

$\mathrm{Al}_{2} \mathrm{O}_{3}$ ) targets respectively, of better than $99.9 \%$ purity. The metal targets used ( $\mathrm{Pt}, \mathrm{Al}$ ) were of $99.99 \%$ purity or better.

Both samples were annealed in flowing nitrogen at $500{ }^{\circ} \mathrm{C}$ for $2 \mathrm{~h}$ after the depositions were completed. Thermocouple-grade platinum wires were bonded to the pads that were connected to a terminal block for interfacing to a computer-based data acquisition system.

A wire of thermocouple-grade Pt-13\%Rh alloy bonded to the common overlapping junction from a fourth platinum pad allowed a hot junction temperature measurement. A gold wire was run from the fourth platinum pad to the terminal block. The cold junction temperature measurement was achieved through a gold wire connected to the pad for the center platinum strip, converted in the data acquisition using a NIST polynomial [20]. A standard Type R thermocouple on a commercial cold junction compensator monitored the terminal block temperature. The use of the gold wires and cold junction compensation was found consistent to within $\pm 2{ }^{\circ} \mathrm{C}$ for room temperature readings of the thermocouples through the data acquisition system, thus setting an uncertainty of the measurements.

The data acquisition system consisted of a multi-channel filter/ amplifier chassis set to gains of 100 and to $5 \mathrm{~Hz}$ low pass. The filter/ amplifier chassis output fed to a computer interface chassis, which in turn communicated with a computer-based data acquisition program that factored out the gains, calculated hot/cold junction temperatures, and recorded the data to a file. The input resistance of the data acquisition system was defined by the $100 \mathrm{M} \Omega$ of the filter/amplifiers and an input bias current of $\pm 2 \mathrm{nA}$ to overcome for a measurement. The system was found to be consistent with calibrated voltage sources to within $\pm 0.5 \%$ and $\pm 0.2 \mu \mathrm{V}$ as used in this study.

The samples were inserted into a cold tube furnace with the cold junction at the edge of the tube mouth. The furnace was then manually ramped in $100{ }^{\circ} \mathrm{C}$ steps as read on the controller every 7 to 10 min while the outputs of the four thermocouples were monitored.
Since the hot and cold junction temperatures were being recorded from directly on the sample, the controller temperature provided feedback for the manual ramp and was not recorded. The voltage output of the thermocouples along with the recorded sample temperatures are shown in Fig. 3.

The $\mathrm{In}_{2} \mathrm{O}_{3} / \mathrm{N}$ : $\mathrm{In}_{2} \mathrm{O}_{3}$ sample unexpectedly split length-wise at a hot junction temperature of $624{ }^{\circ} \mathrm{C}$, ending the test abruptly. No indications in the data suggested that the film was failing. It is believed that there was a slight differential CTE between the alumina substrate and the alumina furnace tube that caused binding of the substrate on the tube walls. As a precaution, the $\mathrm{ZnO} / \mathrm{AlZnO}$ sample was propped away from the wall by a ceramic stand-off to avoid the breakage. The $\mathrm{ZnO} / \mathrm{AlZnO}$ sample survived ramp up to a hot temperature of $1065^{\circ} \mathrm{C}$. However, the high resistance of the $\mathrm{ZnO}$ required a load resistance of $10 \mathrm{k} \Omega$ to record a voltage on the data acquisition system.

The post-anneal resistances were measured with a 4-pt resistance probe having $1.27 \mathrm{~mm}$ spacing, and the resistivities calculated with a standard geometry correction [21]. A summary of the films, deposition gas mixes, thicknesses, resistances, and resistivities is given in Table 1.

Based on the consistent output of the $\mathrm{N}: \mathrm{In}_{2} \mathrm{O}_{3}$ and the $\mathrm{ZnO}$, these material systems were chosen for further characterization. Two thermocouples were patterned with shadow masks on small $25 \mathrm{~mm}$ diameter EBC-CMC samples. The fabrication of the sample followed the fabrication processes described above for the alumina samples. The small size of the EBC-CMC samples available precluded meaningful temperature data from being gathered, but they did provide a method to test the films' survivability on the EBC-CMC surface to high temperatures.

$\mathrm{ZnO}$ vs. $\mathrm{N}$ : $\operatorname{In}_{2} \mathrm{O}_{3}$ thermocouples were then fabricated on EBC-CMC samples, as shown in Fig. 4, and annealled in air for 150 min at $800{ }^{\circ} \mathrm{C}$ and then to beyond $1500{ }^{\circ} \mathrm{C}$. Film thickness was difficult to measure on the rough surface, but was estimated at $1.8 \pm 0.2 \mu \mathrm{m}$ for all films. The ceramic thermocouple films survived the $800{ }^{\circ} \mathrm{C}$ anneal for $150 \mathrm{~min}$, but the $\mathrm{EBC}$ failed during the ramp up in the $1500^{\circ} \mathrm{C}$ anneal.

\section{Results and discussion}

In these tests, the output voltage of each thermocouple material was monitored versus platinum, a common standard material that allows performance of potential thermocouple pairs to be evaluated. However, for a full characterization, the output of the thermocouple material should be to a standard reference temperature as well. Since the cold junction temperature was not held constant, the thermoelectric output of the thermocouples were referenced to a common $0{ }^{\circ} \mathrm{C}$ by determining the Seebeck coefficient at lower temperatures.

The methodology of determining the adjustment for a common temperature reference relies on deriving the lower temperature thermopower of the thermocouple [22]. The thermoelectric voltage output produced by a thermocouple $\left(V_{\text {out }}\right)$ is the difference of the thermoelectric voltage of the cold junction $\left(\varepsilon\left(T_{\text {cold }}\right)\right)$ relative to a standard a

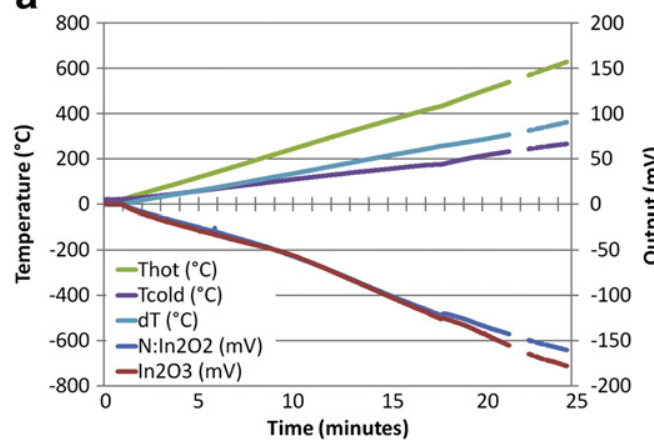

b

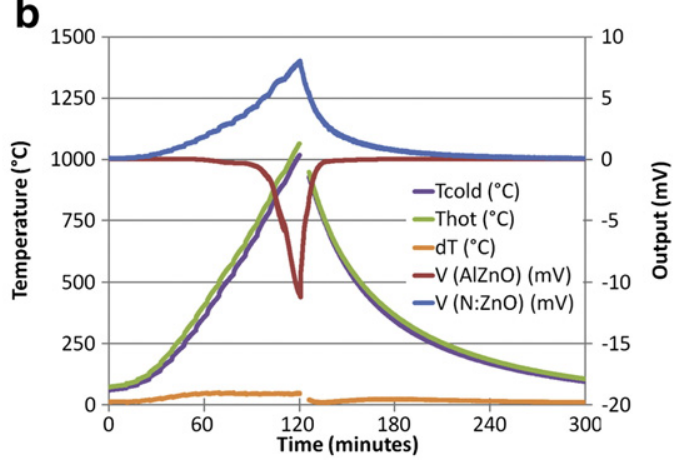

Fig. 3. Thermocouple output and temperatures vs. time for: (a) the $\operatorname{In}_{2} \mathrm{O}_{3} / \mathrm{N}: \mathrm{In}_{2} \mathrm{O}_{3}$ sample; and (b) the $\mathrm{ZnO} / \mathrm{AlZnO}$ sample. 
Table 1

Summary of thin films examined in this study.

\begin{tabular}{|c|c|c|c|c|c|c|c|}
\hline Material & $\mathrm{Ar} / \mathrm{N}_{2} / \mathrm{O}_{2}$ gas mixture $(\mathrm{Pa})$ & Film thickness & Film deposition rate & $\begin{array}{l}\text { 4-pt resistance } \\
\text { (1.27 mm spacing) }\end{array}$ & $\begin{array}{l}\text { Room temperature resistivity } \\
\text { (with geometry corrections) }\end{array}$ & $\begin{array}{l}\text { Estimated } \mathrm{RT} \\
\text { resistance }\left(22^{\circ} \mathrm{C}\right)\end{array}$ & $\begin{array}{l}\text { Estimated resistance } \\
\text { at } 1000{ }^{\circ} \mathrm{C}\end{array}$ \\
\hline $\mathrm{In}_{2} \mathrm{O}_{3}$ & $1.33 / 0 / 0$ & $2.0 \mu \mathrm{m}$ & $2.5 \mathrm{~nm} \cdot \mathrm{min}^{-1}$ & $3.95 \mathrm{k} \Omega$ & $1.43 \Omega \cdot \mathrm{cm}$ & $215 \mathrm{k} \Omega$ & $150 \mathrm{k} \Omega$ \\
\hline $\mathrm{N}: \operatorname{In}_{2} \mathrm{O}_{3}$ & $1.07 / 0.27 / 0$ & $2.0 \mu \mathrm{m}$ & $2.5 \mathrm{~nm} \cdot \mathrm{min}^{-1}$ & $9.08 \mathrm{k} \Omega$ & $3.29 \Omega \cdot \mathrm{cm}$ & $494 \mathrm{k} \Omega$ & $344 \mathrm{k} \Omega$ \\
\hline $\mathrm{ZnO}$ & $1.07 / 0.27 / 0$ & $3.2 \mu \mathrm{m}$ & $2.6 \mathrm{~nm} \cdot \mathrm{min}^{-1}$ & $187.6 \mathrm{M} \Omega$ & $1090 \Omega \cdot \mathrm{m}$ & $10 \mathrm{G} \Omega$ & $2.7 \mathrm{G} \Omega$ \\
\hline $\mathrm{AlZnO}$ & $1.33 / 0 / 0$ & $2.7 \mu \mathrm{m}$ & $1.6 \mathrm{~nm} \cdot \mathrm{min}^{-1}$ & $17.7 \mathrm{M} \Omega$ & $86.6 \Omega \cdot \mathrm{m}$ & $962 \mathrm{M} \Omega$ & $25.6 \mathrm{M} \Omega$ \\
\hline
\end{tabular}

reference subtracted from the voltage produced at the hot junction $\left(\varepsilon\left(T_{\text {Hot }}\right)\right)$ relative to the same reference.

$V_{\text {out }}=\varepsilon\left(T_{\text {Hot }}\right)-\varepsilon\left(T_{\text {Cold }}\right)$

Each junction's voltage is found from the thermocouple's Seebeck coefficient, or thermopower, defined as the change of generated voltage from a thermocouple for a change in temperature. The thermopower $(S)$ is integrated from a reference temperature (typically $0{ }^{\circ} \mathrm{C}$ ) to determine the thermoelectric voltage.

$S(T)=\partial \varepsilon(T) / \partial T$

$\varepsilon(T)=\int_{0}^{T} S\left(T^{\prime}\right) \mathrm{d} T^{\prime}$

In terms of the average temperature $\left(T_{\text {Ave }}=\left(T_{\text {Hot }}+T_{\text {Cold }}\right) / 2\right)$ and temperature difference $\left(\Delta T=T_{\text {Hot }}-T_{\text {Cold }}\right)$, the output of a thermocouple is given as the difference of the integrals at those two temperatures.

$$
\begin{aligned}
V_{\text {out }} & =\varepsilon\left(T_{\text {Hot }}\right)-\varepsilon\left(T_{\text {Cold }}\right)=\varepsilon\left(T_{\text {Ave }}+\Delta T / 2\right)-\varepsilon\left(T_{\text {Ave }}-\Delta T / 2\right) \\
& =\int_{0}^{(T A v e+\Delta T / 2)} S\left(T^{\prime}\right) \mathrm{d} T^{\prime}-\int_{0}^{(T A v e-\Delta T / 2)} S\left(T^{\prime}\right) \mathrm{d} T^{\prime}
\end{aligned}
$$

For $\Delta T / 2 \ll T_{A v e}$, the thermocouple Seebeck coefficient is approximated as $S\left(T_{A v e}\right)$, with the output then defined by $\Delta T$.

$V_{\text {out }}=\varepsilon\left(T_{\text {Hot }}\right)-\varepsilon\left(T_{\text {Cold }}\right) \cong S\left(T_{\text {Ave }}\right) \cdot \Delta T$

Thus, $S(T)$ is determined through a second-order polynomial fit of $\left(V_{\text {out }} / \Delta T\right)$ vs $T_{\text {Ave }}$, which is used to determine $\varepsilon\left(T_{\text {Cold }}\right)$ referenced to $0{ }^{\circ} \mathrm{C}$. Adding $\varepsilon\left(T_{\text {Cold }}\right)$ to the signal $V_{\text {out }}$ gives a more accurate thermopower curve referenced to $0{ }^{\circ} \mathrm{C}$.

$\varepsilon\left(T_{\text {Hot }}\right)=V_{\text {out }}+\varepsilon\left(T_{\text {Cold }}\right) \cong V_{\text {out }}+S\left(T_{\text {Cold }}\right) \cdot \Delta T$

Using this approach, the outputs for the $\operatorname{In}_{2} \mathrm{O}_{3}, \mathrm{~N}: \mathrm{In}_{2} \mathrm{O}_{3}, \mathrm{ZnO}$ and AlZnO vs. platinum thermocouples were referenced to $0{ }^{\circ} \mathrm{C}$, and plotted in Fig. 5. A more precise least-squares third-order polynomial fit with an intercept of $0 \mathrm{mV}$ at $0{ }^{\circ} \mathrm{C}$ was performed on each curve, with the $\mathrm{In}_{2} \mathrm{O}_{3}$

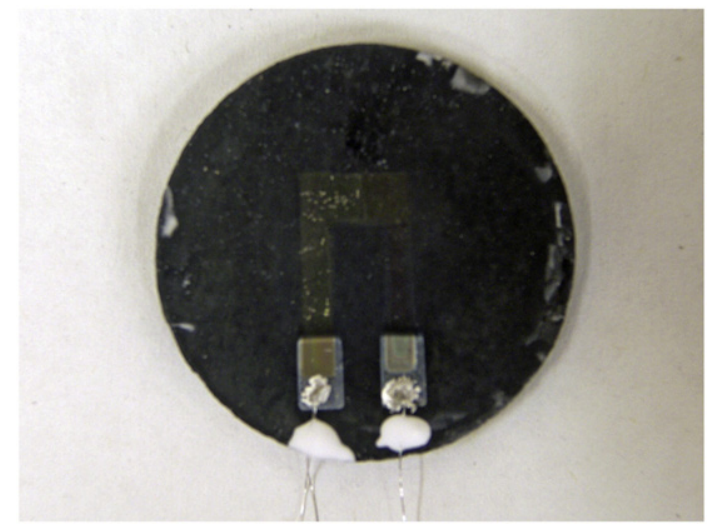

Fig. 4. EBC-CMC sample with $\mathrm{ZnO}$ vs. $\mathrm{N}: \mathrm{In}_{2} \mathrm{O}_{3}$ thermocouple. and $\mathrm{N}$ : $\operatorname{In}_{2} \mathrm{O}_{3}$ fits limited to second order since adding a third order did not improve the fit. The resulting polynomial coefficients with the corresponding $R^{2}$ correlation coefficients are shown in Table 2. To account for the uncertainty in the data acquisition, the $R^{2}$ correlations could be reduced systematically by another 0.00005 for determining the variance $\left(\sigma^{2}=1-R^{2}\right)$.

Previous studies of conductive oxide films gave significant differences from our findings. Chen [23] found $\mathrm{In}_{2} \mathrm{O}_{3}$ resistivity of $22 \mathrm{~m} \Omega \cdot \mathrm{cm}$ and maximum thermopower of $-224 \mu \mathrm{V} \cdot \mathrm{K}^{-1}$, and Gregory [24] found a maximum thermopower of $+256 \mu \mathrm{V} \cdot \mathrm{K}^{-1}$ for $\mathrm{ZnO}$. Though our resistivity measurements were 100 times greater than Chen, the fitted thermopower measurements were about twice the values of Chen and Gregory. Variations of these parameters can be due to the variability of the film morphology and large film resistance.

Models for the variation of resistivity and thermopower can be found for a variety of cases [25]. The resistivity $(\rho)$ of semiconducting films can be modeled in the high temperature, low external field case as dependent on an exponential of the activation energy of the film $\left(E_{a}\right)$ (also referred to as the effective work function) scaled by the physical constant of thermodynamic energy to absolute temperature (Boltzmann constant) $(k)$ and the film temperature $(T)$, grain size $(r)$ and spacing $(d)$.

$\rho \propto(r / d) E_{a}^{-1 / 2} \exp \left(E_{a} / k T\right)$

For the limit of the grain size much greater than the grain spacing $(r \gg d)$, the effective work function is inversely dependent on $r$ and $d$, scaled by the physical constants of electromagnetic energy to frequency (Planck constant) $(h)$ and electron rest mass $\left(m_{e}\right)$.

$E_{a}=h^{2} /\left(8 m_{e} r d\right)$

In the free-electron model, the thermopower $(S)$ is derived as inversely proportional to the material's effective work function, scaled by the physical constant of elementary charge (e) and Archimedes' constant $(\pi)$.

$S=-\left(\pi^{2} k^{2} T\right) /\left(e E_{a}\right)$

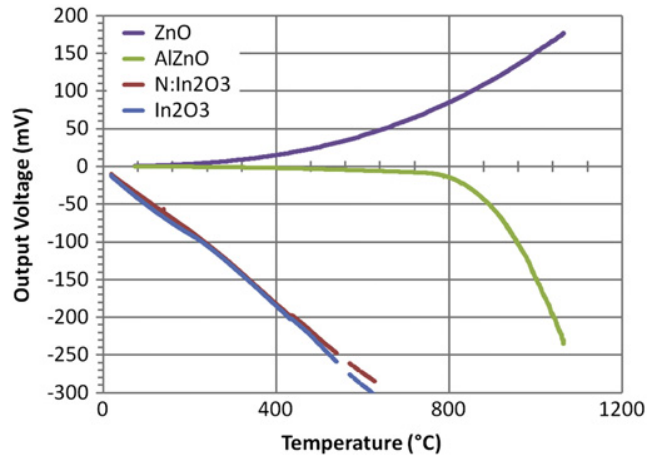

Fig. 5. Graphed thermoelectric output of the tested films vs. platinum referenced to $0{ }^{\circ} \mathrm{C}$. 
Table 2

Fitted coefficients for ceramic thin film thermocouple elements vs. platinum.

\begin{tabular}{|c|c|c|c|c|c|}
\hline & \multicolumn{3}{|c|}{ Fitted coefficients for $\mathrm{V}(\mathrm{T})=\mathrm{A} \cdot \mathrm{T}^{3}+\mathrm{B} \cdot \mathrm{T}^{2}+\mathrm{C} \cdot \mathrm{T}$} & \multirow{2}{*}{$\begin{array}{l}\text { Fitted } \\
\text { thermopower } \\
\text { at } 1000{ }^{\circ} \mathrm{C}\end{array}$} & \multirow{2}{*}{$\begin{array}{l}\text { Correlation } \\
\text { coefficient } \\
\left(R^{2}\right)\end{array}$} \\
\hline & $\mathrm{A}\left(\mathrm{mV} \cdot \mathrm{C}^{-3}\right)$ & $\mathrm{B}\left(\mathrm{mV} \cdot \mathrm{C}^{-2}\right)$ & $\mathrm{C}\left(\mathrm{mV} \cdot \mathrm{C}^{-1}\right)$ & & \\
\hline $\mathrm{AlZnO}$ & $-6.2555 \times 10^{-7}$ & $6.2366 \times 10^{-4}$ & $-1.3789 \times 10^{-1}$ & $-767 \mu \mathrm{V} \cdot \mathrm{K}^{-1}$ & 0.94284 \\
\hline $\mathrm{ZnO}$ & $9.0647 \times 10^{-8}$ & $6.0437 \times 10^{-5}$ & $-4.0611 \times 10^{-4}$ & $+392 \mu \mathrm{V} \cdot \mathrm{K}^{-1}$ & 0.99997 \\
\hline $\mathrm{N}: \mathrm{In}_{2} \mathrm{O}_{3}$ & - & $-5.5409 \times 10^{-5}$ & $-4.2638 \times 10^{-1}$ & $-537 \mu \mathrm{V} \cdot \mathrm{K}^{-1}$ & 0.99931 \\
\hline $\mathrm{In}_{2} \mathrm{O}_{3}$ & - & $-7.8046 \times 10^{-5}$ & $-4.3241 \times 10^{-1}$ & $-589 \mu \mathrm{V} \cdot \mathrm{K}^{-1}$ & 0.99773 \\
\hline
\end{tabular}

However, due to the lack of agreement of Eq. (9) in materials with electrons restricted to either the valence or conduction bands, modifications are invoked in the work function and bulk resistivity due to deviations in film density or grain size from bulk. For example, phonon drag of the electron flow has also been cited as contributing to variations of resistivity and thermopower for various films [23], with the thermopower due to the phonon $\operatorname{drag}\left(S_{g}\right)$ added to the thermopower due to electron drift $\left(S_{D}\right)$.

$S=S_{g}+S_{D}=S_{g}-\left(\pi^{2} k^{2} T\right) /\left(e E_{a}\right)$

The term $S_{g}$ has been derived as proportional to the square root of the resistivity change due to phonon drag $\left(\rho_{g}\right)$, the material's lattice thermal conductivity $\left(k_{L}\right)$ and inverse of the temperature [26].

$S_{g}=\sqrt{ }\left(\left(\rho_{g} k_{L}\right) / T\right)$

The thermal conductivity itself is a combination effect of the electron drift over a mean free path, which varies in the free-electron model as exponential of $E_{a} / k T$ (i.e., proportional to the resistivity), and phonon scattering, which varies as a function of $T^{3}$ [25]. Thus, the resistivity and thermopower reactions from phonon drag are non-linear with temperature, and the change of the thermopower due to phonon drag is expected to be seen as an " $\mathrm{S}$ " curve deviation in the thermopower.

Resistivity and thermopower are also modeled to vary from bulk based on the ratio of film thickness to electron mean free path, which is also dependent on the film's effective work function [25]. Based on reported thermopower for films of various thicknesses [25,27], the electron mean free path is less than $200 \mathrm{~nm}$ for sputtered noble metal films. For films greater than $2 \mu \mathrm{m}$ as we have used in this work, the film thickness is not considered an issue.

The resistance of the thermocouples relative to the input resistance of the data acquisition system has a role in variations in the thermopower measurements. The voltages read by the data acquisition system are not truly open-circuit, but across the load resistance of the system, in this case $100 \mathrm{M} \Omega$. Any resistance of the thermocouple will affect the voltage measurement of the thermocouple at the data acquisition system.

The measured voltage output for the thermocouples $\left(V_{M}\right)$ will be scaled from the voltage generated by the thermocouple $\left(V_{T C}\right)$ by a factor based on the average resistance of thermocouple $\left(R_{T C}\right)$ and the input resistance of the measurement system $\left(R_{M}\right)$, as in Eq. (12).

$V_{M}=V_{\mathrm{TC}} /\left[1+R_{\mathrm{TC}} / R_{M}\right]$

The relation in Eq. (12) reflects the voltage loss due to the resistance of the thermocouple, which varies as in Eq. (7).

In Fig. 5, the nearly linear responses for the $\mathrm{In}_{2} \mathrm{O}_{3}$ and $\mathrm{N}: \mathrm{In}_{2} \mathrm{O}_{3}$ thermocouples reflect the low thermocouple resistance relative to the input resistance of the data acquisition system. The activation energy for $\mathrm{InO}_{2}$ is estimated at $12 \mathrm{meV}$ [28], making the resistance drop from room temperature to $1000{ }^{\circ} \mathrm{C}$ only $30 \%$. The AlZnO thermocouple, though with a resistance nearly 10 times the input resistance of the data acquisition system, shows a marked increase of thermopower over $700{ }^{\circ} \mathrm{C}$.
This increase is more indicative of an increase of thermal conductivity resulting in a decrease of phonon drag. The upward increase of the $\mathrm{ZnO}$ signal is more pronounced than expected from resistance change of the sample, and appears to show an increase in thermal conductivity as well.

For the case of $\mathrm{ZnO}$, the thermocouple resistance was so large $\left(R_{T C} \approx 10 \mathrm{G} \Omega\right.$ ) that a $10 \mathrm{k} \Omega$ resistor was put in parallel with the $100 \mathrm{M} \Omega$ input resistance to allow the 2 nanoamps to flow for a voltage reading. With an activation energy of $120 \mathrm{meV}$ [29], the resistance of the $\mathrm{ZnO}$ should not fall more than $77 \%$ over the $1000^{\circ} \mathrm{C}$ temperature change. The output of the $\mathrm{ZnO}$ vs. Pt thermocouple should ideally be multiplied by a factor of over 600,000 times for the true open-circuit voltage, but these values would never be realized in practical use due to the large thermocouple resistance and low current.

\section{Conclusions}

There is a need for reliable, non-intrusive surface temperature measurements of EBC-CMC systems over $1500^{\circ} \mathrm{C}$, which can be met by the suitable application of ceramic-based sensors. In moving forward in our work on thin film sensors for harsh environment use, we examined several conductive ceramics for use as thin film thermocouples for use on EBC-CMC systems.

Sputtered oxides AlZnO, $\mathrm{ZnO}, \mathrm{In}_{2} \mathrm{O}_{3}$ and $\mathrm{N}: \mathrm{In}_{2} \mathrm{O}_{3}$ were examined in this study. Thermopower curves referenced to $0{ }^{\circ} \mathrm{C}$ vs. platinum were derived from data collected during temperature ramps of thermocouple samples. The zinc oxides appeared to have an extremely high resistance and thus increased complexity as a thermocouple, but indium oxides appeared have a strong, nearly linear response from room to high temperatures. No instabilities of the ceramic films from disassociation or vaporization in the high temperature environments were seen.

The most promising of the thermocouples of each oxide, $\mathrm{ZnO}$ and $\mathrm{N}$ : $\mathrm{In}_{2} \mathrm{O}_{3}$, were demonstrated to survive to high temperature on an EBC-CMC sample. Similar tests of other conductive oxides are planned, and application to components fabricated of EBC-CMC systems is envisioned when the $\mathrm{EBC}-\mathrm{CMC}$ technology becomes available.

\section{Role of funding source}

The funders of the study had no role in study design, data collection, data analysis, data interpretation, or writing of the report. The corresponding author had full access to all the data in the study and had final responsibility for the decision to submit for publication.

\section{Acknowledgments}

The authors would like to acknowledge the support of Kimala Laster and Beth Osborn of Sierra Lobo, Inc., José Gonzalez of Gilcrest Electric, and Charles Blaha of Jacobs Technology, all as part of the NASA Glenn Research Center Test Facilities Operations, Maintenance, and Engineering organization, for the fabrication of the thin film test samples. We also would like to thank Dr. Gary Hunter and Dr. Lawrence Matus of the NASA Glenn Research Center Sensors and Electronics Branch for their technical review and comments of this paper. This work was sponsored at NASA Glenn Research Center by the Vehicle Systems Safety 
Technologies project of the Aviation Safety program and the Supersonics project of the Fundamental Aeronautics program, both part of the NASA Aeronautics Research Mission Directorate.

\section{References}

[1] D.G. LaChapelle, M.E. Noe, W.G. Edmondson, H.J. Stegemiller, J.D. Steibel, D.R. Chang, 34th AIAA/ASME/SAE/AASEE Joint Propulsion Conference \& Exhibit, Cleveland, OH, July 13-15, 1998, AIAA-1998-3266, 1998.

[2] D. Zhu, N.P. Bansal, R.A. Miller, NASA TM-2003-212544, National Aeronautics and Space Administration, Washington, DC, 2003.

[3] J.D. Wrbanek, G.C. Fralick, NASA TM-2006-214395, National Aeronautics and Space Administration, Washington, DC, 2006.

[4] J.F. Lei, H.A. Will, Sens. Actuators, A 65 (1998) 187.

[5] D. Anson, D.W. Richerson, in: M. van Roode, M.K. Ferver, D.W. Richerson (Eds.) Progress in Ceramic Gas Turbine Development, Volume 1 - Ceramic Gas Turbine Design and Test Experience, ASME Press, New York, 2002, p. 1.

[6] B. Schenk, M.L. Easley, D.W. Rickerson, in: M. van Roode, M.K. Ferver, D.W. Richerson (Eds.), Progress in Ceramic Gas Turbine Development, Volume 1 - Ceramic Gas Turbine Design and Test Experience, ASME Press, New York, 2002, p. 77.

[7] S.R. Levine, A.M. Calomino, M.J. Verrilli, D.J. Thomas, M.C. Halbig, E.J. Opila, J.R. Ellis, NASA TM-2003-212493, National Aeronautics and Space Administration, Washington, DC, 2003.

[8] X.L. Peng, T.W. Clyne, Thin Solid Films 312 (1998) 219.

[9] D.S. Campbell, in: L.I. Maissel, R. Glang (Eds.), Handbook of Thin Film Technology, McGraw-Hill, New York, 1970, p. 12.

[10] D.M. Mattox, Thin Solid Films 18 (1973) 173.

[11] N.P. Bansal, J. Eur. Ceram. Soc. 29 (2008) 525.

[12] J.A. DiCarlo, H.M. Yun, G.N. Morscher, R.T. Bhatt, NASA TM-2004-213048, National Aeronautics and Space Administration, Washington, DC, 2004.
[13] S.W. Bradstreet, in: I.E. Campbell, E.M. Sherwood (Eds.), High Temperature Materials and Technology, Wiley, New York, 1967, p. 235.

[14] K.N. Lee, R.A. Miller, N.S. Jacobson, J. Am. Ceram. Soc. 78 (1995) 705.

[15] G.V. Samsonov, P.S. Kislyi, High-Temperature Nonmetalic Thermocouples and Sheaths, Consultants Bureau, New York, 1967.

[16] J.D. Wrbanek, G.C. Fralick, G.W. Hunter, NASA TM-2006-214466, National Aeronautics and Space Administration, Washington, DC, 2006.

[17] O.J. Gregory, E. Busch, G.C. Fralick, X. Chen, Thin Solid Films 518 (2010) 6093.

[18] J.D. Wrbanek, G.C. Fralick, G.W. Hunter, D.M. Zhu, K.L. Laster, J.M. Gonzalez, O.J. Gregory, NASA TM-2010-216216, National Aeronautics and Space Administration, Washington, DC, 2010.

[19] K.N. Lee, D.S. Fox, J.I. Eldridge, D. Zhu, R.C. Robinson, N.P. Bansal, R.A. Miller, J. Am. Ceram. Soc. 86 (2003) 1299.

[20] G.W. Burns, G.F. Strouse, B.M. Liu, B.W. Mangum, Temperature, its Measurement and Control in Science and Industry, vol. 6, American Institute of Physics, New York, 1992.

[21] F.M. Smits, Bell Syst. Tech. J. 37 (1958) 711.

[22] J.D. Wrbanek, G.C. Fralick, S.C. Farmer, A. Sayir, C.A. Blaha, J.M. Gonzalez, NASA TM2004-213211, National Aeronautics and Space Administration, Washington, DC, 2004.

[23] X. Chen, O.J. Gregory, M. Amani, J. Am. Ceram. Soc. 94 (2011) 854.

[24] O.J. Gregory, M. Amani, J. Electrochem. Soc. 158 (2011) J15.

[25] K.L. Chopra, Thin Film Phenomena, McGraw-Hill, New York, 1969.

[26] R.P. Huebener, Phys. Rev. 146 (1966) 502.

[27] K.G. Kreider, G. Gillen, Thin Solid Films 376 (2000) 32.

[28] V.D. Das, S. Kirupavathy, L. Damodare, N. Lakshminarayan, J. Appl. Phys. 79 (1996) 8521.

[29] M. Labeau, P. Rey, J.L. Deschanvres, J.C. Joubert, G. Delabouglise, Thin Solid Films 213 (1992) 94. 